\title{
ELECTROSPUN POLYCAPROLACTONE NANOFIBERS AND MICROBEADS LOADED WITH DEXAMETHASONE FOR EXTENDED OCULAR DRUG DELIVERY
}

Sheng-Po Fang ${ }^{1}$, Kuan-Hui Hsu', Chang-Lin Lin' ${ }^{2}$, Anuj Chauhan ${ }^{2}$, and Yong-Kyu Yoon ${ }^{1}$

${ }^{1}$ Electrical and Computer Engineering, University of Florida, Gainesville, Florida, USA

${ }^{2}$ Chemical Engineering, University of Florida, Gainesville, Florida, USA

\begin{abstract}
A dexamethasone (DX) loaded electrospun polycaprolactone (PCL) nanofibers/microbeads hybrid drug release system is fabricated and characterized. Drug release profiles change for the different ratio of nanofibers and microbeads, which is controlled by the electrospinning parameters such as the solution viscosity and the tip-to-collector distance. Also, it is observed that the electrospun nanofibers/microbeads show enhanced polymer orientation and crystallinity, resulting in significantly lower diffusivity than that of the spin-cast structures. The hybrid system shows an extended release time longer than a month.
\end{abstract}

\section{INTRODUCTION}

Ocular drug delivery using traditional eye drops suffers from limited absorption due to the barrier of corneal epithelium and rapid precorneal loss with tears [1]. Alternatively, direct intravitreal injection is used, which could cause retinal detachment, hemorrhage, endophthalmitis, and cataract [2]. Controlled release over an extended period of time with reduced injection frequency is desired.

Electrospinning is an economic fabrication method for producing nanofibers [3]. Microbeads are formed when the electrospinning conditions are altered. As the sizes of nanofibers and microbeads are different, the release profiles of embedded drug differ, which can be exploited for controlled release. Figure 1 shows a hybrid release system consisting of nanofibers serving as a fast releasing medium and binders between microbeads, while microbeads release drug much slowly, showing two release profiles. Figure 2 shows the schematic of the electrospinning process and the resultant polymer architecture of nanofibers and mibrobeads. Solution viscosity and tip-to-collector distance (TCD) affect the morphology [4-5]. Microbeads are formed in a low viscous condition due to low surface tension. Small TCD produces excessive residual solvent in fibers, transitioning to microbeads.

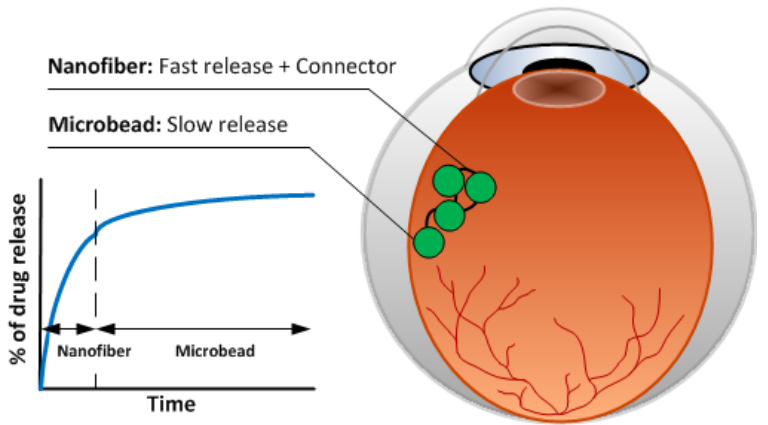

Figure 1:Schematic of a hybrid controlled drug release system with two release profile from nanofibers and microbeads.

Polycaprolacton (PCL) is a biodegradable polymer with a long biodegradation profile [6]. Dexamethasone (DX) is known to relieve ocular symptoms caused by infection, allergies and persistent macular edema. In this work, a DX loaded electrospun PCL hybrid nanofiber/microbead system is demonstrated for controlled release. Four samples are fabricated in different polymer viscosity and TCD conditions. Two solvents are used. Composition and operational parameters are summarized in Table 1. An electric field strength of $1 \mathrm{kV} / \mathrm{cm}$ is used for electrospinning.

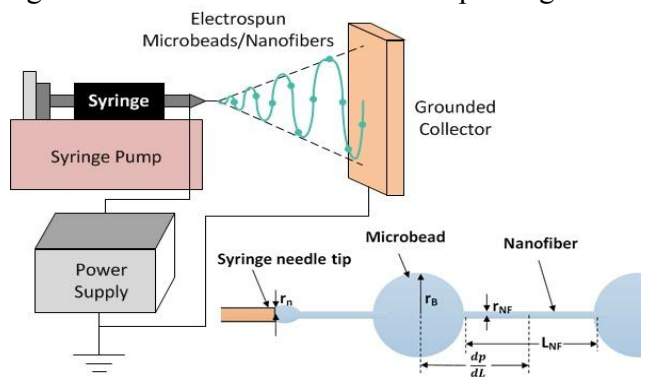

Figure 2: Schematic of the electrospinning setup and polymer parameters for the analytical modeling of diameters.

\section{RESULTS AND DISCUSSIONS}

Figure 3 shows SEM images of the fabricated samples. Samples 1 and 2 with different solvents show pure nanofiber morphology with an average diameter of $307.4 \mathrm{~nm} \pm 8.2 \mathrm{~nm}$ and $669.4 \mathrm{~nm} \pm 342.5 \mathrm{~nm}$, respectively. It shows the nanofiber diameter relies on solvent properties. Hybrid nanofibers and microbeads are observed in Samples 3 and 4, where the PCL concentration is diluted. The microbead diameters are $1.56 \mu \mathrm{m} \pm 0.6 \mu \mathrm{m}$ and 3.68 $\mu \mathrm{m} \pm 1.5 \mu \mathrm{m}$, respectively. The volume percentage of microbeads increases by decreasing TCD from $40.15 \%$ to over $90 \%$.

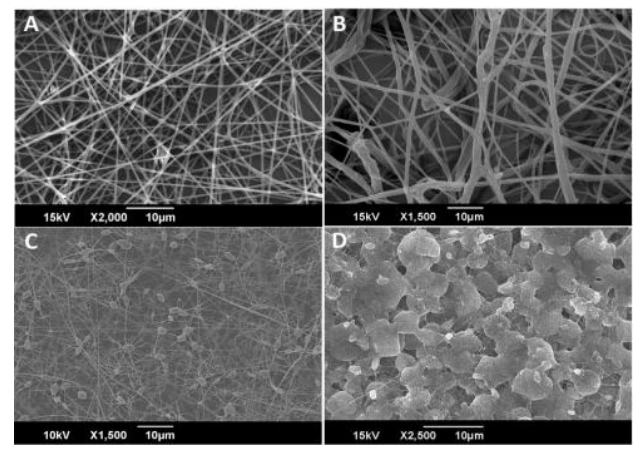

Figure 3: SEM images of electrospun $16 \mathrm{wt} / \mathrm{vol} \%$ of PCL in $(A)$ $D C M / D M F$ and $(B)$ acetone/ethanol, and $4 \mathrm{wt} / \mathrm{vol} \%$ of PCL in $D C M / D M F$ with (C) $12.5 \mathrm{~cm}$ and (D) $7.5 \mathrm{~cm}$.

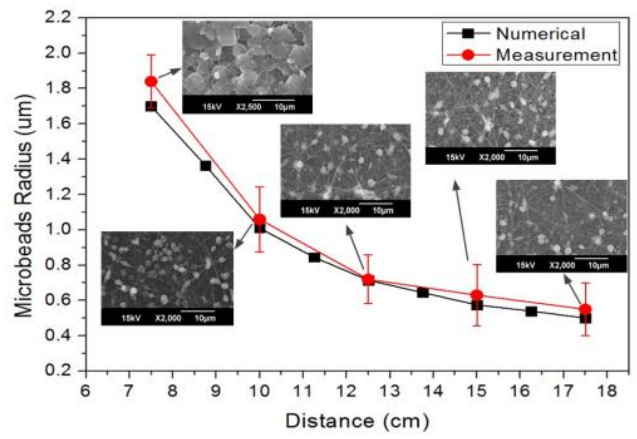

Figure 4: Analytical model prediction and measurement of the microbead radius with varying tip-to-collector distance.
Solid-State Sensors, Actuators and Microsystems Workshop Hilton Head Island, South Carolina, June 5-9, 2016 
An analytical model for the dimensions of nanofibers/microbeads is obtained using the volume conservation theory and flow rate equation shown in (1) and (2).

$$
\begin{aligned}
& 4 / 3 \pi r_{M B}{ }^{3}+\pi r_{N F}^{2} L_{N F}=C \\
& Q=(d p / d L) A_{n}
\end{aligned}
$$

where $r_{M B}, r_{N F}, L_{N F}, d p / d L$, and $A_{n}$ are the microbead radius, nanofiber radius, nanofiber length, pressure gradient, and crosssection area of the needle tip. Figure 4 shows the microbead radius based on the model prediction and experimental results.

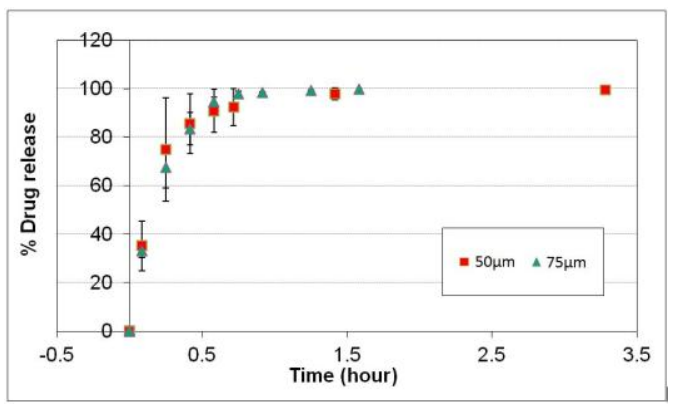

Figure 5: Drug release of nanofiber stacks with different thickness.

The release profiles of nanofiber stacks with different thicknesses are shown in Figure 5. Figure 6 shows the drug release profile of all samples. Samples 1 and 2 have similar profiles within 10 hours. The releasing time of Sample 3 is around 18 days, more than 40 times extended. Sample 4 shows less than $90 \%$ of drug released within 1 month.

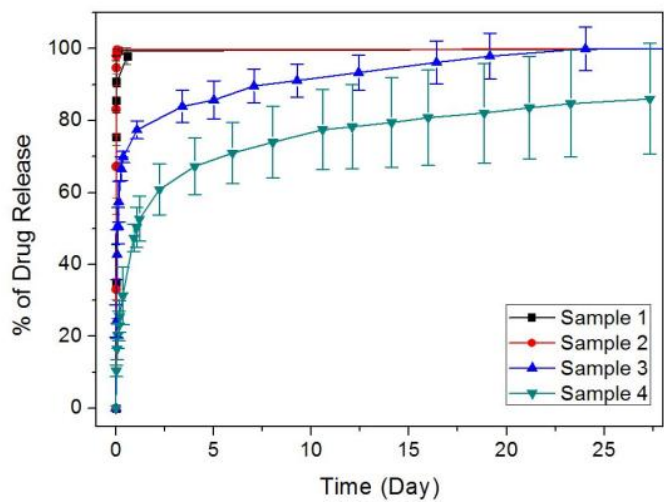

Figure 6: Release profile of pure nanofibers and hybrid samples.

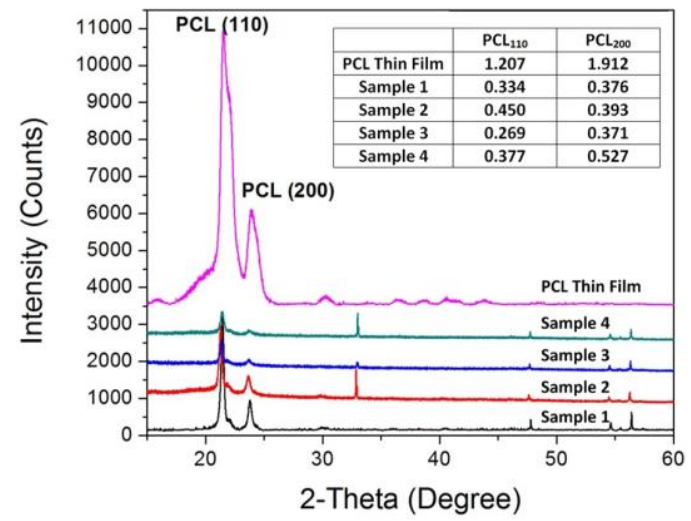

Figure 7: X-ray diffraction measurement of electrospun PCL nanofibers/microbeads and spin-cast PCL thin film.

Figure 7 shows the X-ray diffraction (XRD) measurements to study the effect of polymer orientation. Electrospun samples are compared with spin-cast thin film. Full-width-half-maximum (FWHM) extractions show that electrospinning can enhance polymer crystallinity and orientation due to external electrostatic force and stress. The properties of all the samples are summarized in Table 1.

Table 1: Summary of pure nanofiber and hybrid structure.

\begin{tabular}{|l|c|c|c|c|}
\hline & Sample 1 & Sample 2 & Sample 3 & Sample 4 \\
\hline Solvent & $\begin{array}{c}16 \mathrm{wt} / \mathrm{vol} \% \\
\text { DCM/DMF* }\end{array}$ & $\begin{array}{c}16 \mathrm{wt} / \mathrm{vol} \% \\
\text { Acetone/ } \\
\text { ethanol }\end{array}$ & $\begin{array}{c}4 \mathrm{wt} / \mathrm{vol} \% \\
\text { DCM/DMF* }\end{array}$ & $\begin{array}{c}4 \mathrm{wt} / \mathrm{vol} \% \\
\text { DCM/DMF* }\end{array}$ \\
\hline TCD (cm) & 12.5 & 12.5 & 12.5 & 7.5 \\
\hline $\begin{array}{l}\text { Nanofiber } \\
\text { diameter (nm) }\end{array}$ & 300 & 670 & 108 & 92 \\
\hline $\begin{array}{l}\text { Nanofiber } \\
\text { Volume \% }\end{array}$ & 100 & 100 & 59.85 & 8.70 \\
\hline $\begin{array}{l}\text { Microbead } \\
\text { Diameter (nm) }\end{array}$ & N/A & N/A & 1500 & 3680 \\
\hline $\begin{array}{l}\text { Microbead } \\
\text { volume \% }\end{array}$ & N/A & N/A & 40.15 & 91.30 \\
\hline $\begin{array}{l}\text { Nanofiber } \\
\text { diffusivity } \\
\left(10^{-11} \mathrm{~mm}^{2} / \mathrm{hr}\right)\end{array}$ & 111.0 & $1286.5 \pm$ & $18.07 \pm$ & $2.59 \pm 0.48$ \\
\hline $\begin{array}{l}\text { Microbead } \\
\text { diffusivity } \\
\left(10^{-11} \mathrm{~mm}^{2} / \mathrm{hr}\right)\end{array}$ & N/A & N/A & $14.27 \pm$ & $97.34 \pm$ \\
\end{tabular}

*DCM/DMF: Dichloromethane/Dimethylformamide

\section{CONCLUSIONS}

An electrospun PCL hybrid drug release system consisting of nanofibers and microbeads was developed. It continuously releases DX over a month at room temperature. The hybrid system provides continuous long term delivery and localization of the microbead in the eye. XRD data show the electrospinning process results in lower diffusivity polymer structures. This process could be favorably used as an infrequent treatment alternative.

\section{REFERENCES}

[1] S. Tamilvanan and S. Benita, "The potential of lipid emulsion for ocular delivery of lipophilic drugs," Eur. J. Pharm. Biopharm., vol. 58, pp. 357-368, 2004.

[2] G.E. Sanborn, R. Anand, and R.E. Torti, "Sustained-release ganciclovir therapy for treatment of cytomegalovirus retinitis," Arch Ophthalmol, vol.110, pp.188-195, 1992.

[3] D. Li and Y. Xia, "Electrospinning of Nanofibers: Reinventing the Wheel?," Advance Materials, vol. 16, no. 14 pp. 1151-1170, 2004.

[4] Y.M. Shin, M.M. Hohman, M.P. Brenner, G.C. Rutledge, "Electrospinning: a whipping fluid jet generates submicron polymer fibers," Appl. Phys. Letter, vol. 78, no. 8, pp.1149, 2001.

[5] S.K. Tiwari and S.S. Venkatraman, "Importance of viscosity parameters in electrospinning: Of monolithic and core-shell fibers," Materials Science and Engineering C, vol. 32, pp. 1037-1042, 2012.

[6] J. Venugopal, Y.Z. Zhang, and S. Ramakrishna, "Fabrication of modified and functionalized polycaprolactone nanofibre scaffolds for vascular tissue engineering," Nanotechnology, vol.16, pp.2138-42, 2005.

\section{ACKNOWLEDGEMENT}

Travel support has been generously provided by the Transducer Research Foundation.

\section{CONTACT}

*Yong-Kyu Yoon, Tel: +1- 352-392-5985; ykyoon@ece.ufl.edu 